\title{
PETROLOGIA DAS SUÍTES PALEOPROTEROZOICAS PACIÊNCIA E CATOLÉ DA PORÇÃO SETENTRIONAL DO DOMÍNIO PORTEIRINHA (MINAS GERAIS)
}

\author{
Vinicius Henrique Sena', Anna Luíza Rocha de Oliveira', Alexandre de Oliveira Chaves ${ }^{1 *}$ \\ 1 - Departamento de Geologia - Instituto de Geociências - Universidade Federal de Minas Gerais (IGC-UFMG). vsenageo@gmail.com; \\ annaluiza0604@gmail.com; alochaves@yahoo.com.br (*autor correspondente).
}

Recebido em 29 de dezembro de 2017; aceito em 20 de junho de 2018

\begin{abstract}
Resumo: O Domínio Porteirinha, constituído por gnaisses de composição tonalítica-trondhjemítica-granodiorítica (TTG) migmatizados e por vezes milonitizados, está localizado no extremo norte de Minas Gerais e apresenta uma evolução geotectônica que teve início no Arqueano (3,37 Ma), tendo sido retrabalhado ao longo do tempo geológico. Intrusivas neste domínio, as suítes magmáticas Paciência e Catolé, respectivamente de composição monzosienítica e granítica, exibem texturas magmáticas bem preservadas. A Suíte Paciência (2,05 Ga) constitui uma série álcali-cálcica a alcalina, saturada em sílica, metaluminosa, pós-colisional a orogênica tardia em relação à orogênese Riaciana-Orosiriana regional. É formada essencialmente por monzonitos e sienitos de granulação média a grossa, com mineralogia composta basicamente por feldspato potássico, plagioclásio, anfibólio, biotita e quartzo. Estas rochas derivam da cristalização fracionada de um magma lamprofírico. Já a Suíte Catolé (1,79 Ga), classificada como pós-orogênica a anorogênica, é formada por granitos peraluminosos, de granulação média a fina e com mineralogia composta basicamente por quartzo, microclina, plagioclásio, biotita e muscovita. Classificados como do tipo $A 1$, os granitos da suíte Catolé são interpretados como produtos da cristalização fracionada de magmas basálticos intraplaca com afinidade OIB, relacionados a atividade de uma pluma mantélica envolvida nos processos tafrogenéticos regionais no início do período Estateriano.
\end{abstract}

Palavras Chave: Domínio Porteirinha, Suíte Paciência, Suíte Catolé, Petrologia, Paleoproterozoico

Abstract: PETROLOGY OF THE PACIÊNCIA AND CATOLÉ PALEOPROTEROZOIC SUITES OF THE NORTHERN PORTEIRINHA DOMAIN (MINAS GERAIS). The Porteirinha Domain, constituted by tonalitic-trondhjemític-granodioritic (TTG) gneisses, which are migmatized and sometimes milonitized, is located in the extreme north of Minas Gerais and presents a geotectonic evolution that began in Arquean (3.37 Ma), having been reworked over geological time. Intrusive in this domain, the Paciência and Catolé magmatic suites, respectively of monzosyenitic and granitic composition, exhibit well preserved magmatic textures. The Paciência Suite (2.05 Ga) consists of a metaluminous silica saturated alkali-calcic to alkaline series. It is post-collisional to late orogenic related to the regional Rhyacian-Orosirian orogenesis. It consists essentially of monzonites and syenites of medium to coarse grain, with mineralogy composed basically of potassic feldspar, plagioclase, amphibole, biotite and some quartz. These rocks are derived from the fractional crystallization of a lamprophyric magma. The Catolé Suite (1.79 Ga), post-orogenic / anorogenic, is formed by peraluminous medium to fine grain granites, and mineralogy composed basically of quartz, microcline, plagioclase, biotite and muscovite. Classified as A1, the granites from the Catolé Suite apparently are related to fractional crystallization processes of intraplate OIB-like (ocean island basalts) basaltic magmas, related to the activity of a mantle plume responsible for triggering regional taphrogenetic processes at the beginning of the Statherian period.

Keywords: Porteirinha Domain, Paciência Suite, Catolé Suite, Paleoproterozoic, Petrology

\section{INTRODUÇÃO}

A evolução do embasamento do Orógeno Neoproterozoico Araçuaí é marcada pela aglutinação de blocos crustais arqueanos e paleoproterozoicos durante evento orogênico que se estendeu de 2,2 a 2,0 Ga (Barbosa et al., 2013, Silva et al., 2016). Diversos domínios majoritariamente constituídos por ortognaisses formam o embasamento do Orógeno Araçuaí, como os domínios Guanhães e Porteirinha (Figura 1; Noce et al. 2007; Danderfer et al. 2015). Neste evento Riaciano-Orosiriano ocorreu a consolidação do bloco continental São FranciscoCongo, que fazia parte de um extenso continente paleoproterozoico denominado Columbia (Danderfer et al. 2015; Chaves et al., 2016). Danderfer et al. (2015) e Moreira (2017) descrevem feições geológicas que sugerem várias tentativas de ruptura do supercontinente paleoproterozóico, como a formação da bacia intraplaca Espinhaço e magmatismo associado, expressivos enxames de diques máficos e rochas vulcânicas, todos tidos como evidências destas sucessivas tentativas de fragmentação durante a evolução crustal.

10.18285/geonomos.v26i1.1238

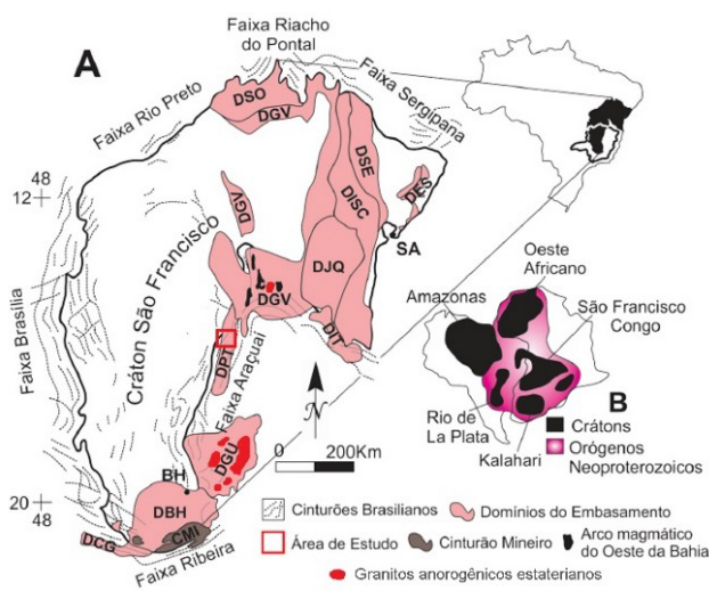

Figura 1. A) O Cráton São Francisco, suas faixas marginais Brasilianas e a localização da área de estudo. Domínios do Arqueano ao Orosiriano: DBH - Domínio Belo Horizonte; DCG Domínio Campos Gerais; DES - Domínio Esplanada; DGU - Domínio Guanhães; DGV - Domínio Gavião; DISC - Domínio ItabunaSalvador-Curaçá; DIT - Domínio Itapetinga; DJQ - Domínio Jequié; DPT - Domínio Porteirinha; DSE - Domínio Serrinha; DSO Domínio Sobradinho; $\mathrm{CMI}$ - Cinturão Mineiro. Cidades: $\mathrm{BH}=$ Belo Horizonte; $S A=$ Salvador. $B)$ Crátons maiores da América do Sul e da África e sua relação com as zonas orogênicas brasilianas-panafricanas que os envolvem, em uma reconstrução esquemática do

Gondwana ocidental (modificado de Silva et al., 2016). 
O Domínio Porteirinha, descrito primeiramente por Drumond et al. (1980), encontra-se na zona mais externa da faixa orogênica Araçuaí (e.g. Noce et al. 2007), próximo de seu limite setentrional, aflorando ao longo da direção N-S (Figuras 1 e 2A). Este domínio compreende rochas arqueanas a paleoproterozoicas, cobertas por rochas metassedimentares estaterianas a criogenianas do Supergrupo Espinhaço e Grupo Macaúbas (e.g. Knauer et al. 2007) (Figura 2B). É composto por gnaisses de composição tonalíticatrondhjemítica-granodiorítica (TTG) migmatizados e por vezes milonitizados, com intercalações de corpos granitoides, anfibolitos, rochas metaultramáficas, sequências metavulcanosedimentares e formações ferríferas bandadas.

Mourão et al. (1997) e Roque et al. (1997), agrupam as rochas paleoproterozóicas intrusivas do Domínio Porteirinha nas Suítes Paciência e Catolé (Figura 2C). A suíte Paciência é composta por lamprófiros com granulação fina a média de cor preta, bem como por monzonitos, quartzo monzonitos e sienitos de granulação grossa, coloração variando de cinza, bege a rosa, e por vezes com fenocristais de feldspato potássico. Em geral estes litotipos apresentam-se isotrópicos, porém localmente podem estar foliados ou mesmo milonitizados, na forma de filonitos esverdeados ricos em epidoto. As rochas pertencentes a Suíte Catolé são granitos de coloração cinza claro, branca a branca rosada ou amarelada, de granulação fina a média. Localmente, as rochas de ambas as suítes são cortadas por diques máficos que podem estar metamorfizados ou não (Mourão et al.1997, Roque et al. 1997, Knauer et al. 2007, Knauer et al. 2015).

Silva et al. (2016) dataram zircões de amostras de sienitos da Suíte Paciência pelo método $\mathrm{U} / \mathrm{Pb}$ e obtiveram idades de 2050 +/- 10 Ma e 2039 +/- 8 Ma. Costa (2013) apresentou datações de U/Pb em zircões de uma amostra da Suíte Catolé e os resultados forneceram idade de cristalização de 1792 +/- $7 \mathrm{Ma}$.

Para auxiliar na compreensão da evolução crustal paleoproterozoica da região investigada, o presente trabalho apresenta os dados petrográficos e o tratamento de análises litoquímicas das suítes Paciência e Catolé, com o intuito de se discutir aspectos petrológicos a elas pertinentes que auxiliam a elucidar o contexto de soerguimento pós-colisional a orogênico tardio Riaciano (registrado pela suíte Paciência), bem como o contexto pós-orogênico a anorogênico Estateriano (registrado pela suíte Catolé), do Domínio Porteirinha.

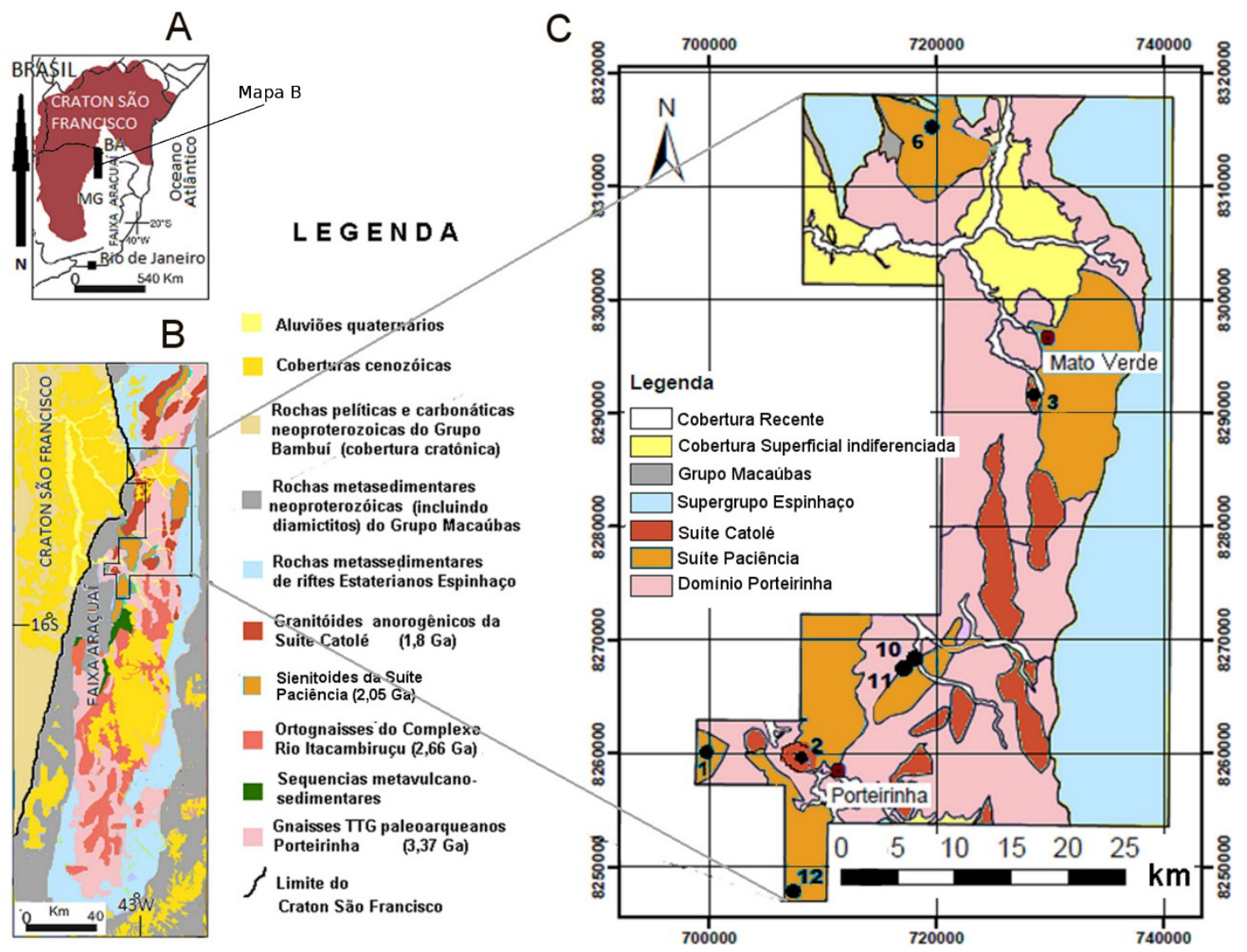

Figura 2. A), B) O Domínio Porteirinha e sua localização na zona mais externa da faixa orogênica Araçuaí. C) Geologia das suítes Paciência e Catolé na porção setentrional do Domínio Porteirinha (modificado de Pinto \& Silva, 2014). As localizações das amostras coletadas estão apresentadas, sendo duas amostras no ponto 6 e duas no ponto 11. 


\section{MATERIAIS E MÉTODOS}

Foram coletadas 9 amostras na porção norte do Domínio Porteirinha, sendo duas da Suíte Catolé e sete da Suíte Paciência (Figura 2), tendo esta última um maior número de amostras pela necessidade de que ela esteja representada pelos seus termos menos (menor sílica) e mais evoluídos (maior sílica) magmaticamente, o que não ocorre com a suíte Catolé (homogênea, sem litotipos diferenciados em campo). Nos laboratórios do Centro de Pesquisa Manoel Teixeira Costa (CPMTC - IGC/UFMG) foram confeccionadas lâminas delgadas das rochas para estudos micropetrográficos. As análises litoquímicas foram realizadas no Laboratório SGS-Geosol, situado em Vespasiano-MG (vide SGS-Geosol, 2018). Após moagem e fusão com metaborato de lítio e digestão nítrica diluída, os elementos maiores e elementos traços (Ba, V, Sr, Zn, Zr) foram analisados por ICP-OES (Espectrometria de Emissão Ótica com Plasma Indutivamente Acoplado). Os demais elementos traços, em conjunto com elementos terras-raras, foram analisados por ICP-MS (Espectrometria de Massas com Plasma Indutivamente Acoplado). A perda ao fogo ocorreu por diferença de peso após aquecimento a $1000^{\circ} \mathrm{C}$. Os dados litoquímicos foram tratados com o auxílio do programa Geoplot.

\section{RESULTADOS}

\subsection{Petrografia}

\section{Suíte Paciência}

A suíte Paciência é composta por rochas plutônicas com textura ígnea preservada, porém localmente encontram-se foliadas. Nesta suíte ocorrem lamprófiros com granulação fina a média e de cor preta, além de monzonitos, quartzomonzonitos e sienitos de granulação grossa, coloração variando de cinza, bege a rosa (Figura 3), por vezes apresentando fenocristais de feldspato potássico.

\section{Lamprófiros Melanocráticos do Tipo Minette / Vogesito}

Afloram na forma de enclaves centimétricos a métricos no interior dos sienitos. Macroscopicamente são rochas holocristalinas de granulação fina a média apresentando predominância de anfibólio e flogopita (esta última por vezes como fenocristais milimétricos). Observamse cristais de feldspato intersticiais em relação aos minerais máficos, além de pequenos cristais de sulfetos disseminados. A rocha apresenta foliação metamórfica sutil. Em lâmina delgada (Figura 4A), este litotipo é inequigranular hipidiomórfico com os minerais máficos anfibólio (hornblenda magmática) e flogopita (muitas vezes sagenítica, com inclusões de agulhas de rutilo), representando cerca de $85 \%$ do volume da rocha. Os cristais de feldspato potássico (microclina) são intersticiais de cristalização tardia. Cristais de plagioclásio são mais raros que os de microclina (fato que permite classificar a rocha como do tipo Minette/Vogesito) e mostram alteração secundária para sericita e epidoto. Ocorrem como minerais acessórios apatita, titanita, rutilo, zircão e opacos (óxidos e sulfetos). Os minerais secundários observados são clorita, além de sericita e epidoto.

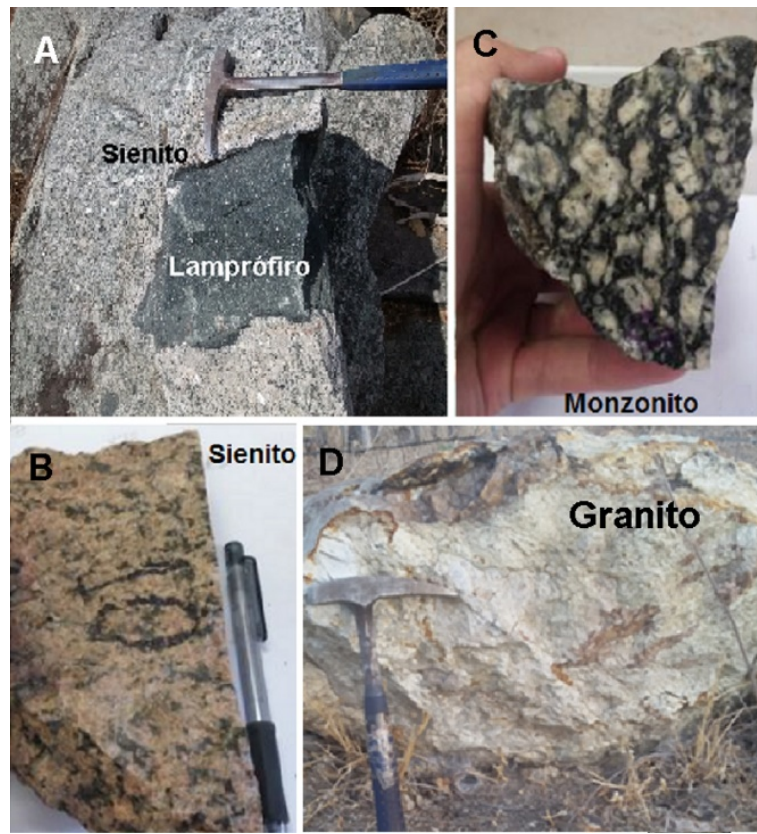

Figura 3. Suite Paciência : $A$ - Lamprófiro (enclave em sienito do ponto 11); $B$ - sienito (ponto 10); $C$ - monzonito (ponto 12). Suite Catolé: D-granito (ponto 3).

\section{Monzonitos Melano- a Mesocráticos}

Macroscopicamente são rochas holocristalinas de granulação grossa, com predomínio de minerais máficos sobre os félsicos. Podem apresentar-se foliados. A porção máfica é composta por anfibólios que predominam em relação a agregados de biotita, enquanto que a porção félsica é composta basicamente de cristais de feldspato. Ocorre titanita marron como mineral acessório, podendo chegar a 3 $\mathrm{mm}$ de comprimento. Ao microscópio (Figura 4B), são litotipos inequigranulares hipidiomórficos nos quais os minerais máficos representam $60 \%$ do volume, havendo o predomínio de hornblenda sobre biotita. Cristais de microclina parcialmente poligonalizados envolvem cristais de anfibólio e biotita e, eventualmente, cristais de plagioclásio, estes últimos quase sempre epidotizados. Os minerais acessórios são titanita, apatita, zircão e eventuais opacos (possíveis sulfetos e óxidos). Quartzo é ausente. Os minerais secundários são epidoto, clorita e sericita, marcando planos de foliação incipientes.

\section{Sienitos Leucocráticos}

Com foliação metamórfica discreta, macroscopicamente são rochas holocristalinas de 
granulação grossa com cristais de feldspato compondo a maior parte da moda, além de cristais prismáticos de hornblenda e agregados de biotita, que predominam em relação ao anfibólio. Ao microscópio (Figura 4C), as rochas são equigranulares hipidiomórficas e os minerais máficos correspondem a $30 \%$ do volume, representados por cristais de anfibólio e biotita cloritizada. Os cristais de microclina são os minerais félsicos predominantes, havendo raros cristais de plagioclásio epidotizados. Quartzo com extinção ondulante representa menos de $5 \%$ do volume da rocha. Os minerais acessórios são apatita, titanita, zircão e eventuais opacos. Os minerais secundários são epidoto, clinozoisita, sericita e carbonatos.
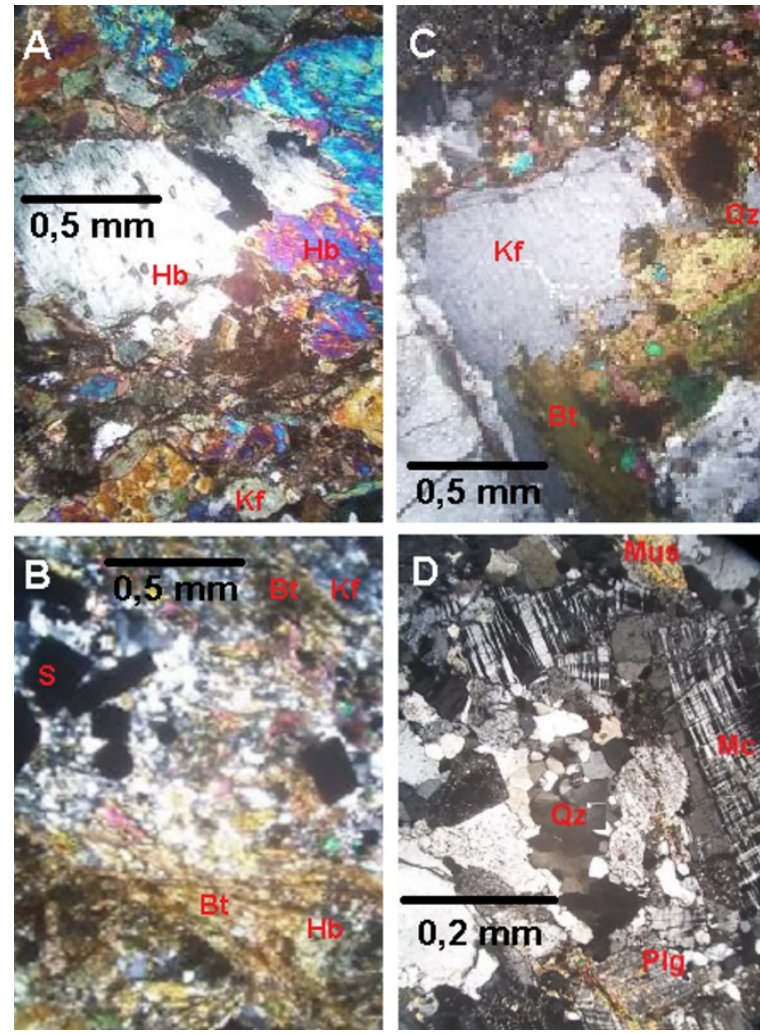

Figura 4. Fotomicrografias de lamprófiro $(A)$, monzonito $(B) e$ sienito (C) da Suite Paciência. $\mathrm{Hb}$ - hornblenda, Fl-flogopita, $\mathrm{Kf}$ feldspato potássico, Bt - biotita, $S$-sulfetos, Qz - quartzo. D Fotomicrografia de granito da Suíte Catolé. Mc - microclina, $Q z-$

quartzo, Plg-plagioclásio, Mus - muscovita.

\section{Suíte Catolé}

As rochas pertencentes a esta suíte são granitos de coloração cinza claro, branca a branca rosada ou amarelada, de granulação média a fina. Podem se apresentar foliados (gnaissificados) e são formados por quartzo, K-feldspato, plagioclásio e micas (Figura 3D).

\section{Granito leucocrático}

Rocha holocristalina de textura equigranular, com granulação média a fina, contendo K-feldspato (35\%), quartzo $(25 \%)$, plagioclásio $(20 \%)$ às vezes epidotizado, biotita e muscovita primárias (10\% de micas). Como acessórios ocorrem minerais opacos, zircão e apatita (Figura 4D).

\subsection{LITOQUÍMICA}

Foram feitas as análises litoquímicas de nove amostras, sendo duas da Suíte Catolé e sete da Suíte Paciência. A Tabela 1 apresenta os dados das análises realizadas, incluindo razões como a $\mathrm{La} / \mathrm{Nb}$ que distinguem as suítes.

No diagrama TAS adaptado para rochas plutônicas (Le Maitre, 2002; Figura 5A), as amostras da Suíte Paciência se localizam essencialmente nos campos dos monzonitos (S3) e sienitos (T) e na porção do diagrama pertencente à série alcalina saturada em sílica. As amostras da Suíte Catolé plotam no campo dos granitos ( $R$ ).

Com relação à saturação em alumina, os granitos a duas micas da Suíte Catolé são caracterizados como peraluminosos. Já as amostras da Suíte Paciência demonstram um caráter metaluminoso pelo diagrama A/CNK vs. A/NK (Maniar \& Piccoli, 1989; Figura 5B). No diagrama $\mathrm{Na}_{2} \mathrm{O}+\mathrm{K}_{2} \mathrm{O}-\mathrm{CaO}$ versus sílica (Frost et al., 2001), as amostras da Suíte Paciência são caracterizadas como pertencentes à série álcalicálcica (campo 3) e as da Suíte Catolé ocupam o campo 5 dos leucogranitos peraluminosos (Figura $5 C)$.

No diagrama de FeOt/MgO versus $10000^{*} \mathrm{Ga} / \mathrm{Al}$ de Whalen et al. (1987), que separa granitos tipo I e $S$ dos granitos tipo A (Figura 5D), foram plotadas as amostras da Suíte Catolé. Observa-se que os granitos constituintes desta suíte são de origem anorogênica (tipo A). No diagrama de Eby (1992), é possível especificar o subtipo de granito A (Figura 5E). O campo A1 corresponde a granitos aparentemente relacionados a fontes do tipo basálticas de ilhas oceânicas (OIB - ocean island. basalts), derivados por cristalização fracionada, e neste campo estão inseridas as amostras da Suíte Catolé. Já no campo A2 ocorrem granitos aparentemente relacionados a fontes crustais (não relacionadas a metassedimentos) ou do tipo arco, derivados a partir da fusão parcial.

No diagrama multicatiônico R1-R2 de Batchelor \& Bowden (1985), que permite a classificação tectônica das rochas (Figura 5F), as amostras da Suíte Paciência correspondem à etapa de soerguimento póscolisional (campo 3) e à fase tardi-orogênica (campo 4). Já os granitos da Suíte Catolé ocupam o campo 7, caracterizado como pós-orogênico.

As amostras da Suite Paciência mostram um maior enriquecimento geral em terras raras $\left(\mathrm{La} / \mathrm{Yb}^{*}\right.$ de 37 a 94) do que os granitos da Suite Catolé ( $\mathrm{La} / \mathrm{Yb}^{*}$ de 14 a 40) no diagrama de terras raras normalizados ao condrito (Figura 5G), porém as anomalias negativas de Eusão mais pronunciadas na suíte Catolé (razões Eu/Eu* de 0,33 a 0,41 contra 0,49 a 0,86 da Suite Paciência). Já no diagrama de elementos incompatíveis normalizados ao Manto Primitivo (Figura $5 \mathrm{H}$ ), há anomalias negativas de $\mathrm{P}, \mathrm{Ti}, \mathrm{Sr}, \mathrm{Ba}, \mathrm{Nb}$ e Ta em ambas as suítes. 
Tabela 1. Análises litoquímicas de litotipos das suítes Catolé e Paciência. FeOt-ferro total expresso como FeO. PF-perda ao fogo. Elementos maiores em \% em peso e demais em ppm. $E u / E u^{*}=E u_{N} / V(S m \times G d)_{N}\left(N-\right.$ normalizada ao condrito). La $/ Y b_{N}{ }^{*}=r a z a ̃ o$ normalizada ao condrito segundo Sun \& McDonough (1989).

\begin{tabular}{|c|c|c|c|c|c|c|c|c|c|}
\hline \multirow{2}{*}{$\begin{array}{c}\text { Unidades } \\
\text { Rocha }\end{array}$} & \multicolumn{2}{|c|}{ Suíte Catolé } & \multicolumn{7}{|c|}{ Suíte Paciência } \\
\hline & Granito & Granito & Sienito & Sienito & Lamprófiro & $\begin{array}{l}\text { Quartzo- } \\
\text { monzonito }\end{array}$ & Monzonito & $\begin{array}{l}\text { Quartzo- } \\
\text { monzonito }\end{array}$ & $\begin{array}{l}\text { Quartzo- } \\
\text { monzonito }\end{array}$ \\
\hline Amostra & 2 & 3A & 10 & $11 \mathrm{~A}$ & 11B & 12 & 1 & 6 & $6 A$ \\
\hline $\mathrm{SiO}_{2}$ & 76,77 & 75,63 & 65,79 & 64,01 & 51,83 & 65,00 & 59,07 & 62,63 & 64,55 \\
\hline $\mathrm{TiO}_{2}$ & 0,08 & 0,07 & 0,78 & 0,73 & 0,74 & 0,75 & 0,83 & 1,49 & 1,55 \\
\hline $\mathrm{Al}_{2} \mathrm{O}_{3}$ & 13,25 & 13,37 & 15,66 & 15,73 & 9,90 & 13,27 & 13,50 & 13,78 & 13,17 \\
\hline FeOt & 1,47 & 1,82 & 3,50 & 5,00 & 10,03 & 5,97 & 8,65 & 6,42 & 6,45 \\
\hline MgO & 0,12 & 0,05 & 0,72 & 1,82 & 12,50 & 2,83 & 5,16 & 2,83 & 2,94 \\
\hline MnO & 0,02 & 0,02 & 0,07 & 0,06 & 0,22 & 0,08 & 0,13 & 0,11 & 0,12 \\
\hline $\mathrm{CaO}$ & 0,34 & 0,33 & 1,97 & 2,70 & 7,84 & 2,83 & 4,28 & 3,09 & 3,18 \\
\hline $\mathrm{Na}_{2} \mathrm{O}$ & 3,77 & 3,50 & 3,09 & 3,09 & 1,01 & 2,78 & 2,34 & 3,00 & 3,13 \\
\hline $\mathrm{K}_{2} \mathrm{O}$ & 4,47 & 5,50 & 6,76 & 6,35 & 4,80 & 5,68 & 5,38 & 4,24 & 4,56 \\
\hline $\mathbf{P}_{2} \mathbf{O}_{5}$ & 0,01 & 0,00 & 0,13 & 0,25 & 0,65 & 0,34 & 0,49 & 0,71 & 0,73 \\
\hline $\mathrm{Cr}_{2} \mathrm{O}_{3}$ & 0,00 & 0,00 & 0,00 & 0,02 & 0,13 & 0,03 & 0,04 & 0,00 & 0,00 \\
\hline PF & 0,26 & 0,20 & 0,76 & 0,71 & 1,41 & 0,28 & 1,21 & 1,24 & 0,91 \\
\hline Total & 100,56 & 100,49 & 99,23 & 100,47 & 101,06 & 99,84 & 101,08 & 99,54 & 101,29 \\
\hline Co & 0,8 & 2,0 & 5,9 & 10,0 & 43,8 & 13,4 & 26,6 & 14,6 & 15,5 \\
\hline $\mathbf{N i}$ & 5,0 & 5,0 & 5,0 & 32,0 & 361,0 & 49,0 & 65,0 & 14,0 & 18,0 \\
\hline $\mathbf{R b}$ & 202,4 & 337,2 & 178,7 & 221,3 & 268,8 & 289,3 & 202,9 & 124,0 & 134,4 \\
\hline $\mathrm{Ba}$ & 314,0 & 264,0 & 362,0 & 1784,0 & 2778,0 & 1479,0 & 2381,0 & 2378,0 & 2247,0 \\
\hline $\mathrm{Sr}$ & 39,0 & 32,0 & 171,0 & 1013,0 & 784,0 & 544,0 & 833,0 & 787,0 & 875,0 \\
\hline $\mathbf{Y}$ & 8,0 & 17,8 & 29,7 & 14,8 & 35,5 & 27,1 & 21,8 & 33,6 & 33,9 \\
\hline $\mathrm{Zr}$ & 86,0 & 165,0 & 873,0 & 804,0 & 259,0 & 404,0 & 101,0 & 551,0 & 607,0 \\
\hline $\mathrm{Nb}$ & 11,7 & 19,1 & 11,3 & 8,4 & 9,6 & 23,5 & 8,8 & 34,1 & 26,4 \\
\hline $\mathrm{Zn}$ & 41,0 & 18,0 & 78,0 & 51,0 & 153,0 & 58,0 & 97,0 & 129,0 & 119,0 \\
\hline Ga & 23,8 & 30,1 & 23,7 & 22,1 & 16,4 & 21,5 & 20,5 & 23,3 & 22,9 \\
\hline $\mathrm{Hf}$ & 3,0 & 8,2 & 20,1 & 18,9 & 6,9 & 11,3 & 2,9 & 12,4 & 13,3 \\
\hline $\mathrm{Ta}$ & 1,0 & 0,9 & 0,5 & 0,8 & 0,4 & 1,7 & 0,4 & 1,4 & 1,3 \\
\hline TI & 0,7 & 0,8 & 0,9 & 1,1 & 1,5 & 1,5 & 1,3 & 0,7 & 0,6 \\
\hline Th & 21,3 & 64,0 & 52,4 & 34,5 & 37,6 & 74,8 & 18,0 & 16,7 & 12,6 \\
\hline $\mathbf{U}$ & 6,4 & 21,4 & 1,7 & 4,2 & 4,2 & 10,1 & 2,5 & 3,3 & 1,1 \\
\hline La & 27,50 & 29,20 & 407,30 & 161,00 & 194,20 & 129,00 & 72,20 & 263,00 & 172,20 \\
\hline $\mathrm{Ce}$ & 44,00 & 50,30 & 658,80 & 282,20 & 348,80 & 232,70 & 124,10 & 426,00 & 322,90 \\
\hline $\mathrm{Pr}$ & 4,50 & 5,81 & 70,95 & 28,14 & 39,80 & 24,95 & 14,38 & 44,75 & 35,23 \\
\hline $\mathrm{Nd}$ & 14,60 & 19,10 & 222,20 & 89,30 & 144,40 & 83,40 & 51,00 & 145,30 & 122,10 \\
\hline Sm & 3,40 & 5,50 & 26,10 & 10,70 & 23,00 & 13,30 & 8,30 & 19,40 & 18,30 \\
\hline Eu & 0,36 & 0,71 & 3,46 & 2,22 & 4,84 & 2,24 & 2,14 & 4,01 & 3,83 \\
\hline Gd & 3,17 & 5,02 & 17,30 & 7,09 & 17,13 & 10,09 & 6,98 & 14,88 & 14,26 \\
\hline $\mathrm{Tb}$ & 0,42 & 0,75 & 1,93 & 0,82 & 1,87 & 1,22 & 0,88 & 1,74 & 1,66 \\
\hline Dy & 1,78 & 3,82 & 7,37 & 3,13 & 7,54 & 5,63 & 3,94 & 7,45 & 7,29 \\
\hline Ho & 0,28 & 0,71 & 1,22 & 0,55 & 1,17 & 1,00 & 0,71 & 1,26 & 1,24 \\
\hline Er & 0,61 & 1,84 & 3,20 & 1,59 & 2,94 & 2,61 & 1,93 & 3,14 & 3,14 \\
\hline $\mathrm{Tm}$ & 0,08 & 0,25 & 0,46 & 0,21 & 0,36 & 0,36 & 0,23 & 0,39 & 0,38 \\
\hline $\mathrm{Yb}$ & 0,50 & 1,50 & 3,10 & 1,50 & 2,10 & 2,30 & 1,40 & 2,40 & 2,40 \\
\hline $\mathrm{Eu} / \mathrm{Eu}^{*}$ & 0.33 & 0.41 & 0.49 & 0.78 & 0.74 & 0.59 & 0.86 & 0.72 & 0.72 \\
\hline $\mathrm{La} / \mathrm{Yb}^{*}$ & 39.45 & 13.96 & 94.24 & 76.99 & 66.33 & 40.23 & 36.99 & 78.60 & 51.46 \\
\hline $\mathrm{La} / \mathrm{Nb}$ & 2.35 & 1.53 & 36.04 & 19.17 & 20.23 & 5.49 & 8.20 & 7.71 & 6.52 \\
\hline
\end{tabular}



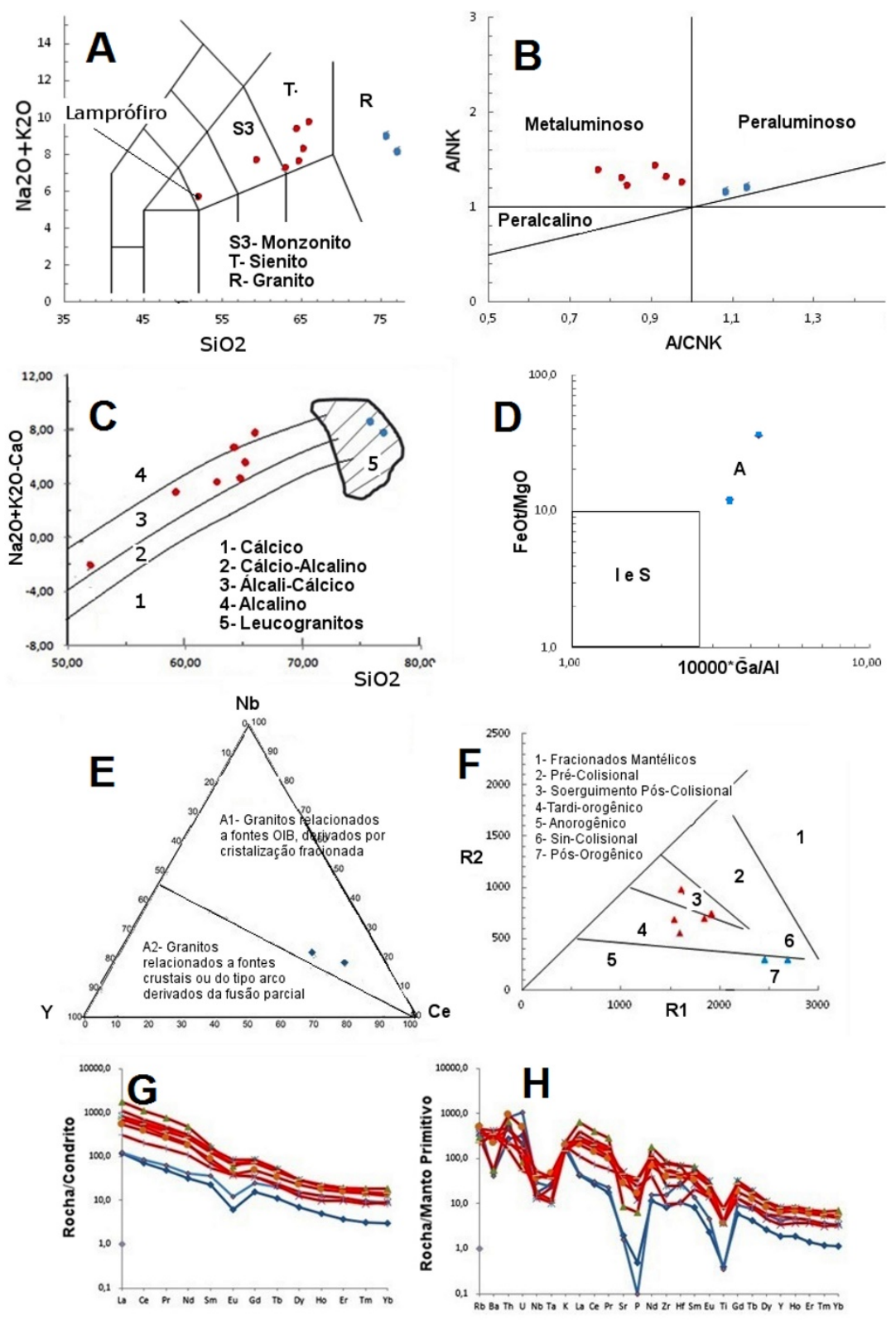

Figura 5. A) Diagrama TAS (Le Maitre, 2002). B) Diagrama A/CNK vs. A/NK (Maniar \& Piccoli, 1989). C) Diagrama de Frost et al. (2001). D) Diagrama 10000*Ga/Al versus FeOt/MgO (Whalen et al. 1987). E) Diagrama triangular Y-Nb-Ce de Eby (1992). F) Diagrama multicatiônico R1-R2 de Batchelor \& Bowden (1985). G) Diagrama de Terras Raras com normalização ao Condrito segundo Sun \& McDonough (1989). H)

Diagrama de elementos incompatíveis com normalização ao Manto Primitivo segundo McDonough \& Sun (1995). Amostras da Suite Paciência em vermelho e Suíte Catolé em azul.

\section{DISCUSSÕES E CONCLUSÕES}

As anomalias negativas de Eu mais pronunciadas na suíte Catolé (razões Eu/Eu* de 0,33 a 0,41 contra 0,49 a 0,86 da Suite Paciência) são possivelmente associadas ao fracionamento do plagioclásio durante a evolução desde os magmas basáticos sugeridos pelo diagrama da figura $5 \mathrm{E}$. No diagrama de elementos incompatíveis (Figura $5 \mathrm{H}$ ), as anomalias negativas de $\mathrm{P}$ e Ti são indicadores da cristalização fracionada dos minerais acessórios apatita e óxidos de Fe-Ti. Já as anomalias negativas em Sr e Ba indicam o fracionamento do plagioclásio no qual são compatíveis. Em suas considerações sobre associações ígneas tardi-orogênicas mundo afora,
Bonin (2004) postula que o enriquecimento da fonte mantélica das associações alcalinas vincula-se a processos de metassomatismo provocados pela subducção da fase pré-colisional. Segundo Pearce (2014), a subducção de litosfera oceânica leva à liberação de fluidos aquosos para dentro da cunha do manto situada logo acima dela. Estes fluidos carregam consigo elementos extraídos da placa em subducção, como os LILE (large ion lithophile elements $-\mathrm{K}, \mathrm{Rb}, \mathrm{Ba}, \mathrm{Sr}$ ), os ETRL (elementos terras raras leves como La, Ce e Nd), Th e U. A maior concentração dos elementos mais móveis na subducção (Th, La e $K$ ) em relação aos mais imóveis ( $\mathrm{Nb}$ e Ta) produz a anomalia negativa de Nb e Ta típica deste sistema. A subducção na região estudada 
possivelmente ocorreu para oeste sob o arco magmático Riaciano do Oeste da Bahia (Cruz et al., 2016) mostrado na figura 1.

Durante a consolidação do bloco continental São Francisco-Congo ocorreram aglutinações de fragmentos crustais arqueanos no período Riaciano (Barbosa et al., 2013) que foram precedidas por subducção, como no caso do arco magmático do Oeste da Bahia (Figura1) situado no domínio Gavião nas proximidades do Domínio Porteirinha (Cruz et al., 2016). Na etapa de soerguimento pós-colisional a orogênica tardia Riaciana do Domínio Porteirinha, houve o posicionamento dos monzonitos e sienitos da Suíte Paciência há 2,05 Ga. A suíte desenvolveu-se como uma série álcali-cálcica, metaluminosa e saturada em sílica. Segundo Chaves (2015), a mesma faz parte de um domínio estrutural N-S com mais de $1000 \mathrm{~km}$ de comprimento nos estados de Minas Gerais e Bahia, ao longo do qual outras suítes alcalinas semelhantes ocorrem.

A partir da constatação das anomalias negativas de $\mathrm{Nb}$ e Ta da Suite Paciência (Figura $5 \mathrm{H}$ ), é possível sugerir que a fusão parcial do manto litosférico, que provavelmente havia sido previamente metassomatizado por fluidos derivados da placa subductada antes da colisão que teria envolvido o Domínio Porterinha, teria gerado um magma melanocrático lamprofírico saturado em sílica, rico em álcalis e hidratado o bastante para dele cristalizar anfibólio e flogopita. A diferenciação por cristalização fracionada deste magma lamprofírico teria levado ao surgimento e posicionamento dos monzonitos. Estes monzonitos, por sua vez, evoluíram para os sienitos (muitos deles com enclaves dos lamprófiros), os termos mais evoluídos da Suíte Paciência. O processo de diferenciação magmática por cristalização fracionada é suportado pelos diagramas de Harker de $\mathrm{SiO}_{2}$ versus óxidos de elementos maiores (Figura 6), nos quais linhas de tendência evolutiva são claramente percebidas.

Na fase pós-orogênica a anorogênica, já no início do período Estateriano há 1,79 Ga, houve a formação dos granitos peraluminosos da Suíte Catolé (Figuras $5 \mathrm{D}$ e 5F). Esta granitogênese anorogênica de ambiente tectônico extensional intraplaca continental esteve vinculada à processos de cristalização fracionada de magmas basálticos intraplaca do tipo ilhas oceânicas (OIB - ocean island. basalts), relacionados a atividade de uma pluma mantélica sugerida por Chaves et al. (2016), tendo em vista que no diagrama da figura $5 \mathrm{E}$, os granitos Catolé se classificam como granitos A1. Knauer et al., (2007) descrevem abundantes enclaves máficos nos granitos Catolé, que possivelmente representam restos do magma basáltico do qual teria se diferenciado. Possivelmente, o material desta pluma interagiu com o manto litosférico pré-existente, adquirindo as anomalias negativas de $\mathrm{Nb}$ e Ta percebidas nos granitos da Suite Catolé (Figura 5H). A idade de 1792 +/- $7 \mathrm{Ma}$ da Suite Catolé é similar não só à idade de 1780-1730 Ma dos granitos anorogênicos Borrachudos (Fernandes et al., 1994), localizados no Domínio Guanhães da figura 1, como também à idade de 1750 Ma dos granitos anorogênicos São Timóteo (Turpin et al., 1988), localizados no Domínio Gavião da figura 1 , ambos os quais podem ter sido gerados durante a atividade da pluma sugerida por Chaves et al. (2016).
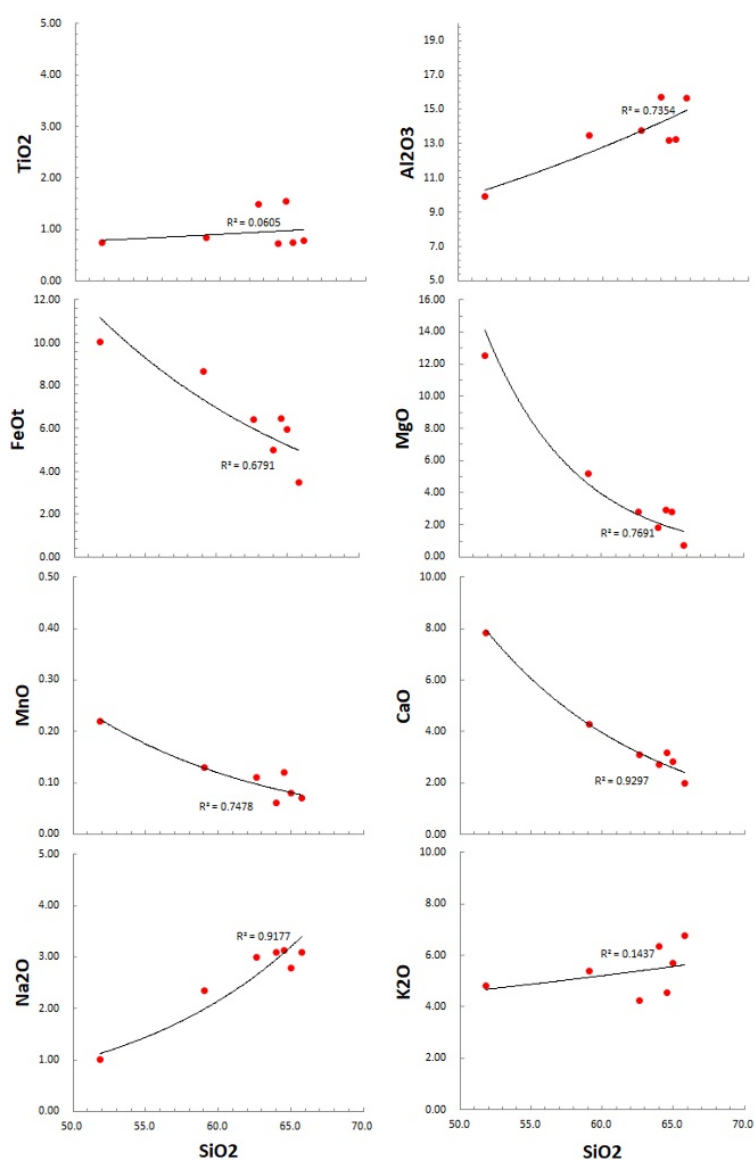

Figura 6. Diagramas de variação (tipo Harker) de $\mathrm{SiO}_{2}$ versus óxidos de elementos maiores para a Suite Paciência.

Por fim, a atividade da pluma teria sido responsável por disparar processos tafrogenéticos regionais no início do período Estateriano, aos quais o rifte Espinhaço (Figura 2) de mesma idade está associado (Danderfer et al., 2015).

\section{AGRADECIMENTOS}

Ao Centro de Pesquisa Manoel Teixeira Costa, CPMTC - IGC/UFMG pelo apoio logístico. Aos revisores e editor pelas contribuições científicas.

\section{REFERÊNCIAS BIBLIOGRÁFICAS}

Barbosa, N.S., Teixeira, W., Leal, L.R.B., Leal, A.B.M., 2013. Evolução crustal do setor ocidental do Bloco Arqueano Gavião, Craton do São Francisco, com base em evidências U-Pb, Sm-Nd e Rb-Sr. Geologia USP. Série Cient. 13(4):63-88. 
Batchelor, R.A. \& Bowden, P. 1985. Petrogenetic interpretation of granitoid rock series using multicationic parameters. Chem. Geol, 48:43-55.

Bonin B. 2004. Do coeval mafic and felsic magmas in postcollisional to within-plate regimes necessarily imply two contrasting, mantle and crustal, sources? A review. Lithos, 78: 1-24.

Chaves, A.O. 2015. Correlações entre suítes magmáticas alcalinas orosirianas pós-colisionais da Bahia e de Minas Gerais: fragmentos de uma província alcalina? Bol. Mus. Paraense Emílio Goeldi, Cienc. Nat., 10(2):179-197.

Chaves, A.O., Fonseca, W.M., Leal, V.L.S. 2016. Províncias ígneas gigantes e o reposicionamento dos proto-crátons sulamericanos em Columbia na transição-Orosiriano-Estateriano. Bol. Mus. Paraense Emílio Goeldi, Cienc. Nat., 11(2):263-280.

Costa, A.F.O. 2013. Estratigrafia e tectônica da borda oeste do Espinhaço Central no extremo norte da faixa Araçuaí, Minas Gerais. Departamento de Geologia, Universidade Federal de Ouro Preto, Ouro Preto, Dissertação de Mestrado, 170p.

Cruz, S.C.P., Barbosa, J.S.F., Pinto, M.S., Peucat, J.J., Paquette, J.L, Souza, J.S., Martins, V.S., Chemale Jr., F., Carneiro, M.A., 2016. The Siderian-Orosirian magmatism in the Archean Gavião Paleoplate, Brazil: U-Pb geochronology, geochemistry and tectonic implications. J. South Am. Earth Sci., 69: 43-79.

Danderfer, A., Lana, C.C., Nalini Júnior, H.A., Costa, A.F.O. 2015. Constraints on the Statherian evolution of the intraplate rifting in a Paleo-Mesoproterozoic paleocontinent: New stratigraphic and geochronology record from the eastern São Francisco craton. Gondwana Res., 28(2):668-688.

Drumond, J.B.V., Von Sperling, E., Raposo, F.O. 1980. Projeto Porteirinha-Monte Azul. Belo Horizonte, DNPM-CPRM, 559p.

Eby, G.N. 1992. Chemical subdivision of the A-type granitoids: Petrogenetic and tectonic implications: Geology, 20:641-644.

Fernandes, M. L. S., Marciano, V. R. P. R. O., Oliveira, R. C., Correia Neves, J. M., Diláscio, M. V. 1994. Granitos Borrachudos: um exemplo de granitogênese anorogênica na porção central do Estado de Minas Gerais. Geonomos, 2(2): 23-29.

Frost, R. R. 2001. A Geochemical Classification for Granitic Rocks. J. Petrology, 42, 11

Knauer, L.G., Silva, L.L., Souza, F.B., Silva, L.R., Carmo, R.C. 2007. Geologia da Folha Monte Azul, (SD.23-Z-DII). Programa Geologia do Brasil. Brasília: CPRM, CD-ROM.

Knauer, L.G., Fantinel, L.M., Magalhães, J.T.R., Perereia, D.F.L.C. 2015. Folha Gameleiras SD.23-Z-D-I Escala 1:100.000. Projeto Fronteiras de Minas. Programa Mapeamento Geológico do Estado de Minas Gerais, contrato CODEMIG-FUNDEP. Belo Horizonte, Centro de Pesquisa Manoel Teixeira da Costa, Instituto de Geociências, Universidade Federal de Minas Gerais. 57p.
Le Maitre. 2002. Igneous rocks - classification and glossary of terms. Cambridge.

Maniar, P.D. \& Piccoli, P.M. 1989. Tectonic discriminations of granitoids. Geol. Soc. America Bull., 101: 635-643.

McDonough, W.F. \& Sun, S.S. 1995. The composition of the Earth. Chem. Geology, 120: 223-253.

Moreira, H.M. 2017. Caracterização Petrológica, Geoquímica e Geocronológica de corpos Intrusivos Máficos da Porção Central da Serra do Espinhaço, Dissertação de Mestrado UFOP.

Mourão, M. A. A., Grossi-Sad, J. H., Fonseca, E. 1997. Geologia da Folha Janaúba. In: Grossi-Sad, J. H.; Lobato, I. M.; PedrosaSoares, A. C.; Soares-Filho, B.S. (editores). Projeto Espinhaço em CD-ROM (textos, mapas e anexos). Belo Horizonte, COMIG. p. 9-123.

Noce, C.M., Pedrosa-Soares, A.C., Silva da L.C., Alkmim, F.F. 2007. O embasamento Arqueano e Paleoproterozóico do Orógeno Araçuaí. Geonomos, 15(1):17 - 23.

Pearce, J. A. 2014. Geochemical Fingerprinting of the Earth's Oldest Rocks. Geology, v. 42. n. 2. p. 175-176.

Pinto, C.P. \& Silva, M.A. 2014. Mapa geológico do Estado de Minas Gerais. 1:1.000.000. CPRM (Serviço Geológico do Brasil). CDROM.

Roque, N.C., Grossi-Sad, J.H., Noce, C.M., Fonseca, E. 1997. Geologia da Folha Rio Pardo de Minas. In: Grossi-Sad J.H.; Lobato L.M.; Pedrosa-Soares A.C.; Soares-Filho B.S. (editores). PROJETO ESPINHACCO EM CD-ROM (textos, mapas e anexos). Belo Horizonte, COMIG - p. 125 - 221.

SGS-Geosol. 2018.2 Disponível em: https://www.sgsgeosol.com.br/wpcontent/uploads/2016/04/sgsgeosol-lamina-laboratoriogeoquimico.pdf. Acessado em 20 fev 2018.

Silva, L.C., Pedrosa-Soares, A.C., Armstrong, R., Pinto C.P.; Magalhães, J.T.R., Pinheiro, M.A.P., Santos, G.G. 2016. Disclosing the Paleoarchean to Ediacaran history of the Sao Francisco craton basement: The Porteirinha domain (northern Araçuaí orogen, Brazil). J. South Am. Earth Sci., 68: 50-67.

Sun, S.S. \& McDonough, W.F. 1989. Chemical and isotopic systematics of oceanic basalts; implications for mantle composition and processes. In: Magmatism in the ocean basins. Saunders, A.D. and Norry, M.J. (Editors), Geological Society of London, London. 42:313-345.

Turpin, L., Maruejol, P., Cuney, M. 1988. U-Pb, Rb-Sr and Sm-Nd chronology of granitic basement, hidrothermal albitites and uranium mineralization (Lagoa Real, South-Bahia, Brazil). Contributions to Mineralogy and Petrology, 98(2):139-147.

Whalen, J.B., Currie, K.L., Chappell, B.W. 1987. A-types granites: geochemical characteristics, discrimination and petrogenesis. Contrib. Mineral. Petrol., 95:407-419. 